\section{LA INTEGRACIÓN SOCIAL COMO DESAFÍO: ANÁLISIS DEL PROGRAMA DE CAMPAMENTOS EN CHILE (2011-2018) ${ }^{1}$}

Christian Paulo Matus Madrid ${ }^{2}$, Álvaro

Ramoneda ${ }^{3}$ y Felipe Valenzuela ${ }^{4}$

\section{Resumen}

Uno de los principales desafíos para la integración social en las ciudades latinoamericanas es la presencia de asentamientos informales, que alojan a un porcentaje importante de la población urbana empobrecida. Si bien en Chile la informalidad urbana es menos frecuente que en otros países de la región, el reciente crecimiento de los campamentos le otorga una mayor relevancia al problema. En este contexto, el presente artículo estudia los efectos de integración social y exclusión de las políticas dirigidas a asentamientos informales en Chile, específicamente a través del Programa de Campamentos y su ejecución entre 2011 y 2018. Para ello,

\section{THE CHALLENGE OF SOCIAL INTEGRATION: ANALYSIS OF THE 'INFORMAL SETTLEMENTS' PROGRAM' IN CHILE (2011-2018)}

Christian Paulo Matus Madrid, Álvaro Ramoneda y Felipe Valenzuela

\section{Abstract}

One of the main challenges for social integration in Latin American cities is the presence of informal settlements, where a significant percentage of the poorest urban population live. Although in Chile urban informality is less frequent than in other countries of the region, the recent growth of informal settlements bestows greater relevance to the problem. This article studies the effects on social integration and exclusion of policies aimed at informal settlements in Chile, specifically through the execution of the Programa de Campamentos or 'informal settlements' program' between 2011 and 2018. Analysis considers quantitative data 
se analizan los resultados de catastros de campamentos y se realiza un estudio de cuatro casos de estrategias de cierre de campamentos en diferentes regiones del país, a través de un análisis de entrevistas, grupos focales y recorridos colectivos. Los resultados relevan la importancia de incorporar dimensiones como el afecto y apego, el sentido de pertenencia y la participación en la generación de integración social, lo que permite discutir las perspectivas sobre la integración que se basan exclusivamente en la cercanía espacial.

PALABRAS CLAVE: ASENTAMIENTOS INFORMALES, INTEGRACIÓN SOCIAL, POLÍTICAS PÚBLICAS URBANAS, CAMPAMENTOS, CHILE

Recibido: 27-06-2019

Aceptado: 16-10-2019 from Informal Settlements' Surveys, and the study of four cases in different regions in the country focusing on strategies aimed at informal settlement closure strategies through a qualitative analysis of interviews, focus groups and walking tours. The results reveal the importance of dimensions such as affect and attachment, sense of belonging and participation in the generation of social integration, thus allowing for the discussion of perspectives on integration that are based exclusively on spatial proximity.

KEYWORDS: INFORMAL SETTLEMENTS, SOCIAL INTEGRATION, URBAN PUBLIC POLICY, SHANTY TOWNS, CHILE

Received: 27-06-2019

Accepted: 16-10-2019
1 Estudio financiado por Ministerio de Vivienda y Urbanismo (Chile), licitación pública ID-587-13-LE18 “La vida después del campamento. Estudio de casos en las regiones de Atacama, Valparaíso, 0’Higgins y Metropolitana".

2 Chile. Profesor adjunto Instituto de Estudios Urbanos y Territoriales, Pontificia Universidad Católica de Chile, http://orcid. org/0000-0002-4874-7635. Correo electrónico: cumatus@uc.cl
3 Chile. Dirección de Extensión y Servicios Externos, Facultad de Arquitectura, Diseño y Estudios Urbanos, Pontificia Universidad Católica de Chile, http://orcid.org/0000-0002-7193-3006. Correo electrónico: alvaro.ramoneda@gmail.com

4 Chile. Profesor adjunto Instituto de Estudios Urbanos y Territoriales, Pontificia Universidad Católica de Chile, http://orcid. org/0000-0003-0096-9500. Correo electrónico: fevalenzuela@ uc.cl 


\section{Introducción}

El presente artículo se propone analizar y reflexionar sobre los efectos de integración social y exclusión que han generado las políticas públicas dirigidas a asentamientos informales en Chile, particularmente las intervenciones del Programa de Campamentos durante la última década (período 2011-2018). A partir de su evaluación cuantitativa, en base a análisis de catastros, y cualitativa, a través de estudios de caso, propone un enfoque multidimensional y multi-escalar al fenómeno de los campamentos, que permita estudiar la integración social en los nuevos conjuntos de vivienda que reúnen tanto a pobladores de campamentos como a pobladores que acceden a vivienda a través de un subsidio individual.

La primera sección aborda una contextualización de antecedentes del fenómeno de los asentamientos informales en Latinoamérica y Chile, sintetizando su abordaje actual desde la política pública. La segunda sección presenta una discusión teórica general sobre integración social y exclusión urbana, que finaliza abordando cómo dichas problemáticas se tematizan en el contexto particular de los asentamientos informales. La tercera parte aborda el análisis de las políticas urbanas dirigidas a asentamientos informales en el contexto de la última década. Por un lado, se analiza la tendencia de desarrollo y diversificación de los campamentos que plantean los catastros levantados por el Ministerio de Vivienda y Urbanismo (MINVU) entre 2011 y 2018. Por otro, se profundiza en un análisis de las estrategias implementadas de abordaje a través de las estrategias de radicación y relocalización de campamentos, a partir de una muestra de cuatro estudios de casos representativa de diferentes variantes del modelo de intervención. En la cuarta sección se presentan las conclusiones del artículo dirigidas a proponer un enfoque particular de comprensión de la integración social en las políticas dirigidas a asentamientos informales, entregando recomendaciones para un abordaje integral del fenómeno.

\section{REVISIÓN DE ANTECEDENTES: LOS ASENTAMIENTOS INFORMALES Y EL DESAFÍO DE LA INTEGRACIÓN DESDE LA POLÍTICA PÚBLICA}

En Latinoamérica, según estimaciones del Participatory Slum Upgrading Programme [PSUP] (2016), el 21\% de la población urbana habita en asentamientos informales. Desde ese marco institucional son definidos como áreas donde sus habitantes no tienen seguridad de tenencia, los barrios carecen de servicios básicos e infraestructura, y las viviendas suelen contravenir las regulaciones de planificación y construcción (ONU-Habitat, 2015). Si bien autores como Abramo (2012) plantean que es posible constatar presencia de informalidad 
urbana ya en tiempos de la ciudad colonial, existe consenso en que los asentamientos informales se establecen en Latinoamérica en las primeras décadas del siglo XX, como parte de los procesos de migración rural-urbana en que los pobres se apropian del espacio urbano para establecer sus viviendas. (Calderón, 2016; Clichevsky, 2009; Di Virgilio, 2015; Fernandes, 2011; Jaramillo, 2008). La masiva migración desde el campo a las ciudades devela rápidamente la incapacidad de los mercados formales de vivienda y de suelo de absorber la creciente demanda (Calderón, 2016), generando además el agotamiento de las alternativas de vivienda de bajo costo como los cuartos de alquiler (Di Virgilio, 2015). Mientras las respuestas estatales resultan insuficientes, en todos los países de la región se desarrollarán diferentes modalidades de ocupación informal del suelo que pueden ser consideradas como procesos de "producción social del hábitat" (Romero, 2012). Es así como los sectores populares "construyen ciudad" a través de estrategias de autoproducción de vivienda (Turner, 1977) y ocupación del espacio como las tomas de sitio, ocupaciones semi-legales e ilegales, aportando a la urbanización de las ciudades latinoamericanas a partir del establecimiento de favelas en Brasil (Andreatta, 2005), invasiones y tomas de terreno en Colombia (Ocampo, 2003; Vargas, Jiménez, Grindlay y Torres, 2010) barriadas en Perú (Saez Giraldez, García Calderón y Roch Peña, 2010), villas miseria en Argentina (Ochsenius, Carman, Lekerman y Wertheimer, 2016), y colonias desarrolladas en los terrenos ejidales en México (Lombard, 2015, entre otros).

En Chile, la expansión desenfrenada de la ciudad de Santiago a partir de los años 30', generará las condiciones para que surjan los primeros asentamientos informales, establecidos como campamentos o "poblaciones callampas" (Espinoza, 1998), urbanizaciones precarias en terrenos cuya propiedad no era clara o correspondía a bienes nacionales de uso público, como las riberas de los ríos y canales de desagüe (Ramón, 1990). Los pobladores asentados en espacios informales serán protagonistas de las primeras tomas de terrenos (Garcés, 2002; Pérez, 2017) organizadas fundamentalmente como respuesta al déficit de vivienda (Equipo de Estudios Poblacionales [CIDU], 1972). No obstante, la trayectoria organizacional desarrollada por el movimiento de pobladores trasciende la demanda exclusiva por vivienda, pudiendo ser interpretada como una respuesta popular temprana a una forma de construir ciudad excluyente (Cortés, 2014). Posteriormente, en dictadura, el movimiento de pobladores será actor protagónico de las jornadas de protesta (Garcés, 2017), sufriendo las consecuencias de las primeras operaciones de relocalización forzada o erradicación en Santiago y Concepción (Morales, Levy, Aldunate y Rojas, 1990). Las nuevas políticas urbanas inspiradas en principios neoliberales, estarán marcadas por la desregulación del mercado de suelo urbano (Sabatini, 2000) y el desarrollo de una política social de 
vivienda en manos del sector privado, con el Estado proporcionando subsidios solo para los grupos de menores ingresos (Pérez, 2017). Las políticas de la primera década de gobierno democrático darán continuidad al modelo de abordaje de los asentamientos informales, fomentando el "éxodo masivo" desde los campamentos a viviendas sociales (Skewes, 2005), marcando la incorporación de los pobres urbanos a relaciones sociales mercantilizadas y trasladando los problemas de integración a los nuevos conjuntos de vivienda social (Rodríguez y Sugranyes, 2005). A partir del nuevo contexto, los pobladores pasarán de ser visualizados como actores sociales revolucionarios (Castells, 1973) a ser valorados como un movimiento urbano que establece como objetivo su integración a la sociedad y no su transformación o lisa y llanamente como agentes individuales receptores de subsidios para la adquisición de viviendas en el mercado privado (López-Morales, Flores y Orozco, 2018).

\section{EL PROGRAMA DE CAMPAMENTOS EN CHILE: EVOLUCIÓN Y DESAFÍOS}

Los asentamientos informales (o campamentos en Chile), han sido abordados desde la política pública a través de diferentes programas (Greene y Cortés, 2018). En el contexto de las políticas de reducción del déficit habitacional que había crecido durante la Dictadura (1973-1990), el tema comenzó a enfrentarse recién a partir de la segunda mitad de la década de los noventa. A partir del gobierno de Frei Ruiz-Tagle el MINVU, plantea como foco inicial mejorar la condición habitacional de las familias más vulnerables del país, a través del programa Chile-Barrio (1996-2005), enmarcado en el Plan Nacional de Superación de la Pobreza, para posteriormente dar paso a la Línea de Atención a Campamentos (2005-2010)(MINVU, 2010). Actualmente, los campamentos son abordados a través del Programa de Campamentos, iniciado a través de un Catastro Nacional realizado en 2011 (MINVU, 2013).

Chile-Barrio constituyó un programa intersectorial que buscaba promover un mejoramiento de la vivienda y el barrio, junto con componentes de habilitación social y laboral, para atender a los 972 asentamientos que habían sido catastrados. De acuerdo a la evaluación de impacto realizada sobre el programa (Ministerio de Hacienda, Dirección de Presupuestos, 2007), el 62\% de los asentamientos obtuvo una solución de radicación y se obtuvieron resultados positivos respecto a la calidad de las viviendas y la satisfacción residencial de los habitantes, pero el impacto fue menos claro en cuanto a la habilitación social y laboral. Pese a que el programa incluía un plan de intervención social, y que se identificaron ciertos factores que podrían promover de mejor forma la participación (Siclari, 2003), el impacto fue menor al esperado, en parte debido a una falta de precisión en los objetivos y metodologías de intervención en este componente (Ministerio de Hacienda, Dirección de Presupuestos, 2007). 
Posteriormente, la Línea de Atención a Campamentos (LAC), operó solamente a través del MIN$\mathrm{VU}$, con foco en entregar soluciones habitacionales a las familias mediante subsidios. Como programa pretendió aportar en el mejoramiento de la calidad de vida de los habitantes de campamentos, utilizando para ello los programas, instrumentos y normativa vigente del MINVU. El paso de Chile-Barrio a LAC fue entonces considerado como una transición que finalmente debía integrar los campamentos en la atención regular del MINVU (2013).

Posteriormente, en 2011 surge el actual Programa de Campamentos del MINVU, que nace con la misión de otorgar una solución habitacional de calidad a las familias que viven en campamentos, con una perspectiva y estrategia "centrada en la superación de la condición de campamento mediante la obtención de soluciones habitacionales definitivas para familias que hoy viven en campamentos, ya sea a través de relocalizaciones o radicaciones, procurando aplicar estrategias integrales que contemplen el cierre de campamentos, en coordinación con entidades públicas y privadas" (MINVU, 2011). En ese marco, será la provisión y acceso a vivienda, y no una mirada más amplia que considere su integración a la ciudad, la que fundamente una política centrada en "formalizar" los asentamientos informales, incorporándolos, a partir de estrategias de radicación y relocalización (MINVU, 2018) a nuevos conjuntos de vivienda, sin reflexionar respecto a los términos poco participativos y asistenciales en que se plantea su integración.

\section{PROBLEMÁTICA Y ESTADO DEL ARTE: LA INTEGRACIÓN SOCIAL Y LA EXCLUSIÓN URBANA EN LAS CIUDADES LATINOAMERICANAS}

El problema de la integración social en las ciudades se ha abordado principalmente en relación a las condiciones de segregación socio-espacial que en general caracterizan a las áreas urbanas. En este sentido, se suele entender la integración social como un resultado de la disminución de la segregación residencial, sin profundizar en otras dimensiones del fenómeno ni en los mecanismos a través de los cuales se produce la integración a nivel local. En este artículo se propone complejizar el concepto de integración en la escala barrial, a partir del estudio de procesos de relocalización o urbanización de asentamientos informales.

\section{INTEGRACIÓN SOCIAL Y SEGREGACIÓN A ESCALA URBANA}

En el contexto latinoamericano, el estudio reciente de los problemas de integración social en las ciudades, se relaciona con las transformaciones económicas experimentadas, con mayor o menor intensidad, por los países de la región desde la década de los ochenta, y sus consecuencias en la 
estructura social. En ese contexto, los trabajos de Kaztman $(2001,2010)$ son relevantes para instalar la discusión respecto al conjunto de condiciones de segregación y exclusión que contribuyen al aislamiento social de los pobres en las ciudades. Este aislamiento sería el resultado de la acción conjunta de la segregación residencial, la precariedad de los vínculos con el mercado del trabajo que mantiene una proporción creciente de la población, y la escasez de espacios de interacción entre diferentes clases sociales (Kaztman, 2001).

La dimensión residencial de la segregación social ha sido tradicionalmente concebida como un fenómeno espacial relacionado con los patrones de localización geográfica de diferentes grupos sociales. Desde esta perspectiva, se ha definido la segregación espacial como "el grado de proximidad espacial o de aglomeración territorial de las familias pertenecientes a un mismo grupo social, sea que este se defina en términos étnicos, etarios, de preferencias religiosas o socioeconómicos" (Sabatini, Cáceres y Cerda, 2001, p. 27). Esta definición busca abarcar al mismo tiempo tanto el grado de concentración de un grupo social en el espacio, como el nivel de homogeneidad social de un espacio delimitado, los que se entienden como dos de las dimensiones de la segregación (Sabatini, Wormald, Sierralta y Peters, 2008). Sin embargo, el tipo de segregación que comúnmente se asocia a problemas de exclusión social es el de la homogeneidad social del espacio, que da lugar a la existencia de "barrios segregados" donde se concentra un alto porcentaje de población pobre y una baja presencia de otros grupos sociales.

Desde una perspectiva procedente de la sociología norteamericana, las consecuencias negativas de la segregación derivarían de la homogeneidad social de estos barrios, donde se produciría el "efecto barrio" y se generarían "guetos" (Massey y Denton, 1993; Wilson, 2012). En buena medida, los estudios realizados sobre segregación residencial en Chile han adoptado esta perspectiva, explicando la presencia de problemas sociales en barrios segregados como un efecto de la ausencia de interacción con otros grupos sociales en el espacio barrial (Arriagada y Morales, 2006; Sabatini, Rasse, Mora, y Brain, 2012; Sabatini et ál., 2001, 2008). De esta interpretación deriva la promoción de políticas de integración residencial, como una manera de solucionar las consecuencias negativas que se atribuyen a la segregación (Sabatini et ál., 2012).

Sin embargo, teniendo en cuenta las particularidades del caso chileno y otros estudios sobre este tema, se pueden enunciar algunas críticas respecto a esta postura teórica para comprender la segregación (Ruiz-Tagle y López, 2014). Si bien el grado de homogeneidad social de un barrio permite identificarlo como un barrio segregado, ello no implica que esta condición sea también el factor que explica las problemáticas que experimenta. En otras palabras, el nivel de homogeneidad social es 
en buena medida una consecuencia de otros procesos sociales e institucionales, que a su vez inciden en reforzar los problemas que estos barrios experimentan.

Por un lado, el proceso de conformación de los barrios de concentración de pobreza, durante las últimas décadas, muestra que los factores que han incidido en su pauperización no están necesariamente relacionados con su nivel de homogeneidad social. En el caso chileno, los barrios que se originaron con la masiva construcción de conjuntos de vivienda social se han caracterizado por problemas de localización, deficiencias de infraestructura y en el acceso a servicios públicos, lo que ha repercutido negativamente en el nivel de satisfacción de sus habitantes (Rodríguez y Sugranyes, 2005). Por otro lado, la homogeneidad social de los barrios tampoco es la explicación exclusiva para los problemas comúnmente atribuidos al efecto barrio, pues este se potencia por condiciones estructurales de desigualdad urbana (por ejemplo, la segmentación escolar) que inciden también en la reproducción de la pobreza. Como contrapartida, la cercanía física entre grupos sociales diferentes no necesariamente implica integración (Ruiz-Tagle, 2016).

En definitiva, para comprender los problemas de integración social, es necesario superar el supuesto de que estos se pueden explicar solamente en función de la poca cercanía con grupos sociales diferentes en el barrio. Ello implica considerar, por un lado, las desigualdades urbanas que afectan las posibilidades de integración funcional y, por otro, los mecanismos más específicos a través de los cuales se puede producir la integración social a escala barrial. Acorde a lo anterior, en el presente artículo se propone analizar las dinámicas de integración y exclusión a escala local, a través del estudio de la aplicación de las estrategias de provisión de vivienda social para la población proveniente de asentamientos informales que realiza el Programa de Campamentos en Chile.

\section{INTEGRACIÓN SOCIAL EN ASENTAMIENTOS INFORMALES}

La idea de integración respecto a los asentamientos informales en Chile se ha complejizado, desde la simple satisfacción de necesidades básicas de vivienda, que caracterizó las políticas de mediados del siglo XX, hacia la demanda por una integración que considere además su localización, la calidad del entorno del barrio y su conexión con la ciudad. Esto en el contexto de nuevos significados vinculados al acceso y el valor de la propiedad de la vivienda, asociado a lo que Salcedo y Rasse (2017) describen como la incorporación de imaginarios de clase media en las representaciones de la pobreza urbana.

En un escenario de globalización económica y desarrollo de procesos de expansión urbana 
excluyente, expresivos de un urbanismo neoliberal (Theodore, Peck y Brenner, 2009), los asentamientos informales incorporan mayor diversidad territorial y cultural, y nuevas lógicas de relación de los pobladores con sus viviendas. Además de la mejora habitacional, demandan acceso a la ciudad y a las oportunidades que ofrecen sus estructuras (Brain, Prieto y Sabattini, 2010; Domínguez, 2011). De esta forma, la noción de "geografía de oportunidades" (Galster y Killen, 1995), adquiere relevancia para entender la integración social de los asentamientos informales en el contexto de una ciudad excluyente y fragmentada, ya que da cuenta de los requerimientos por un mejor acceso a servicios urbanos (educación, salud, consumo) que mejoren su calidad de vida. La localización sería un factor clave para el acceso a oportunidades económicas, laborales y recreacionales, que no se encuentran distribuidas de forma homogénea en la ciudad. Por otro lado, siguiendo a López-Morales et ál., (2018), el incremento del número de campamentos en las principales ciudades chilenas que se visibiliza en la última década, tiene que ver con una diversificación del sujeto que protagoniza la informalidad urbana, que ocupa el asentamiento informal como una táctica de adaptación al escenario de una ciudad excluyente. Se entiende que hoy acceden a vivir en campamentos no solo un componente de hogares previamente allegados, sino que se trata de familias que deben enfrentar aumentos en sus gastos de vivienda, dentro de las cuales destaca una alta tasa de población migrante latinoamericana, existiendo actualmente un proceso de "campamentación" que hace que cualquier persona o familia que se encuentra en situación de vulnerabilidad, que afecte sus posibilidades de cubrir su necesidad de habitabilidad, pueda entrar en situación de campamento (CIS-TECHO Chile, 2015).

A las miradas de la geografía de oportunidades y la campamentación es posible sumar nociones que permiten abordar, desde una perspectiva cualitativa, la integración social en el contexto particular de los asentamientos informales recogiendo conceptos ampliamente abordados en la bibliografía general sobre radicación y relocalización como son el afecto y el apego; el sentido de comunidad; y la participación como capacidad de auto-gestionar el territorio, desarrollados, entre otros, en Fullilove (1996); Lewicka, (2011); Scannell y Gifford, (2010); Berroeta, Ramoneda y Opazo (2015); Camargo y Abiko, (2015); Di Masso y Dixon, (2015); y Berroeta, Carvalho, Di Masso y Ossul (2017). El abordaje del afecto y el apego incorpora al análisis la relación afectiva que el habitante construye con el espacio y territorio, y cómo esta relación se proyecta -en este caso- desde el campamento al nuevo conjunto de vivienda. Se constata que los actores construyen un sentimiento de afecto en relación al hábitat y el entorno del territorio informalmente apropiado (Campos, Silva y Gaete, 2017), que deben ser tomados en cuenta a la hora de generar una 
nueva intervención. Resulta clave valorar la relación que existe entre las personas y su entorno, a partir del apego al lugar, término que remite a la formación de un vínculo emocional hacia los lugares por los individuos, debido a la función que pueden tener en sus vidas (Hernández, Hidalgo, Salazar-Laplace y Hess, 2007; Hidalgo y Hernández, 2001; Lewicka, 2011; Scannell y Gifford, 2010). En ese marco, los aportes de la psicología ambiental pueden ser incorporados como base para entender la integración a nuevos barrios o conjuntos de vivienda a los que se traslada a los pobladores de asentamientos informales. Desde esta perspectiva, se considera la construcción de vínculos de familiaridad (o filiación) con el territorio (Tuan, 2005, p. 1974,), como el marco en que sus habitantes generan la necesidad de cuidarlo, protegerlo y mantenerlo como parte de acciones cotidianas. Esta perspectiva es consistente con la propuesta de desarrollar enfoques de "lugarización" que proponen estudios como los de Lombard (2015) para un abordaje distinto de las colonias populares en México, poniendo en valor su ubicación, localidad y sentido de lugar.

La segunda perspectiva tiene que ver con comprender cómo se conforma, en los nuevos conjuntos de vivienda -que se crean producto de una radicación o relocalización- un sentido de comunidad que permite establecer el reconocimiento de los nuevos habitantes como semejantes (Rinus, Martiniello, Brey, Cachón y Garcés, 2006). Se parte del supuesto de que, en contextos de transformación social y territorial, como los que plantea la radicación y relocalización de asentamientos informales, el sentido de comunidad se debe (re) constituir y preservar, para permitir la integración social. Se reconoce, por tanto, que los pobladores pueden ser sujetos activos en la construcción social de su hábitat (Matus, 2017; Pino y Ojeda, 2013). El sentido de comunidad, genera oportunidades de pertenencia a partir del desarrollo comunitario (McMillan y Chavis, 1986), considerándoselos sujetos, parte de un colectivo más amplio (Sarason, 1974). En este marco, dentro del proceso de socialización de las y los actores que participan del programa de campamentos, es valioso estudiar e indagar en cómo se crea, recrea o no, un sentido de comunidad basado en una historia e intereses compartidos (Long y Perkins, 2003; McMillan y Chavis, 1986; Sarason, 1974).

Por último, la participación constituye una instancia que permite articular barrio constituyéndose en un espacio para racionalizar las interacciones entre personas y estructuras sociales, que conforman los territorios (Ramoneda y Jerez, 2018). Para analizar las diferentes experiencias de construcción de comunidad en el nuevo espacio se debe considerar al menos la participación en dos niveles: el primero, a partir de la pertenencia a entidades o asistencia a actividades (Perkins, Florin, Rich y Wandersman, 1990); y un segundo nivel que considera la participación como el proceso donde los sujetos desarrollan su capacidad de autogestionar, y establecer control sobre su territorio (Arnstein, 1969; Pérez Valecillos, 2009). 


\section{Metodología. Análisis de catastros y estudio de casos del Programa de Campamentos (2011-2018)}

Para estudiar los efectos de integración social de las políticas dirigidas a asentamientos informales en Chile, planteamos un estudio con un enfoque mixto que conjuga análisis cuantitativo y cualitativo. En primer lugar, presentamos el contexto en el que se desarrolla el actual Programa de Campamentos que ejecuta el MINVU, detallando sus principales estrategias para abordar el problema. Junto con ello, se analizan sus resultados en términos cuantitativos, a través del análisis de los catastros realizados en 2011 y 2018.

En segundo lugar, se desarrolla un análisis en base a los principales hallazgos de un estudio de casos desarrollado entre junio y octubre de 2018, en Copiapó, Gran Valparaíso (Quilpué), Región Metropolitana (Lo Espejo) y San Francisco de Mostazal a petición del Departamento de Estudios Habitacionales y Urbanos del MINVU. El trabajo de campo involucró entrevistas semi-estructuradas, grupos focales, recorrido y mapeo participativo

A partir del cruce de ambos análisis se aborda la discusión más amplia de los desafíos y posibilidades que abre, para la política pública urbana, la incorporación de un enfoque de integración social a escala de barrio al actual abordaje que se hace desde el Programa de Campamentos a los asentamientos informales y su inserción en las ciudades.

\section{Resultados}

\section{ANÁLISIS DEL PROGRAMA DE CAMPAMENTOS (2011-2018)}

Para abordar el análisis del Programa de Campamentos se revisó la base de datos del Catastro de 2011 (MINVU, 2013), la base de datos de la última actualización de este catastro (enero 2018), y la versión preliminar de la base de datos del último Catastro Nacional de Campamentos, que finalizará en 2019.

Para la implementación del Catastro Nacional de Campamentos de 2011, se elaboró una definición operativa que entiende estos como "asentamientos preferentemente urbanos, de 8 hogares o más, que habitan en posesión irregular de un terreno, con carencia de al menos uno de los tres servicios básicos", estableciendo como orientación general de la política del Estado el cierre de campamentos (MINVU, 2011).

En base a esta definición, en el Catastro de 2011 se contabilizaron 655 campamentos a nivel nacional, los cuales albergaban a un total de 27.297 familias. Luego de siete años de aplicación del Programa de 
Campamentos, se han declarado como cerrados 361 de estos campamentos, mientras que otros 294 permanecerían vigentes (sin contabilizar los nuevos campamentos surgidos durante la ejecución del programa). Sin embargo, al considerar la cantidad de familias involucradas, la mayoría permanece en campamentos vigentes. Es importante considerar que en muchos casos el "cierre" de un campamento refiere al inicio de la gestión de cierre, lo que no significa necesariamente que las familias hayan dejado efectivamente el campamento.

En términos de metodología de intervención, el programa establece tres estrategias fundamentales (MINVU, 2018):

a. Radicación a partir de un Proyecto Habitacional: las familias obtienen un subsidio habitacional que les permite la construcción de una nueva vivienda y mejoramiento del entorno, en el mismo lugar donde se emplaza el campamento.

b. Radicación a partir de un proyecto de urbanización y consolidación barrial: las familias acceden a servicios básicos, obtienen su título de dominio y consolidan su entorno con opción de mejorar su vivienda, en función del grado de consolidación que esta tenga.

c. Relocalización: las familias obtienen un subsidio habitacional que les permite acceder a una vivienda en un lugar distinto al del campamento. En función del tamaño del campamento, nivel de organización y expectativas de las familias, esta estrategia puede significar un traslado conjunto de la comunidad o de manera individual.

Como se verá más adelante, cada una de estas estrategias presenta desafíos y particularidades desde el punto de vista de la integración social. En términos generales se podría adelantar que las estrategias de relocalización podrían implicar mayor desafío respecto a dimensiones como el apego, el sentido de comunidad y la participación, al enfrentarse a un contexto territorial, y muchas veces social, diferente. Por otro lado, las estrategias de radicación permitirían mantener una mayor continuidad de las dinámicas sociales pre-existentes en los campamentos, pero dependiendo de su ubicación, podrían presentar desafíos en cuanto a la integración funcional a las ciudades donde se localizan.

Como indica la Tabla 1, en la gran mayoría de los campamentos cerrados se aplicó la estrategia de relocalización. En este proceso, a menos que sea una relocalización que se realice por conjunto de campamento, de forma cerrada, en muchos casos implica un proceso de integración con familias que no provienen de campamentos. Mientras tanto, un número considerablemente menor de campamentos ha sido cerrado por la vía de radicaciones, ya sea a través de proyecto habitacional o proyecto de urbanización. 


\section{TABLA 1. PORCENTAJE DE CIERRE Y ESTRATEGIAS DE CIERRE DE CAMPAMENTOS CATASTRADOS EN CATASTRO NACIONAL DE CAMPAMENTOS 2011. INFORMACIÓN ACTUALIZADA A 2018.}

\begin{tabular}{lcccc} 
& \multicolumn{2}{c}{ Campamentos } & \multicolumn{2}{c}{ Familias } \\
& Nro. & $\%$ & Nro. & $\%$ \\
\hline Campamentos cerrados & 361 & $55,1 \%$ & 11410 & $41,8 \%$ \\
\hline Radicación CNT (Proyecto habitacional) & 40 & $6,1 \%$ & 2124 & $7,8 \%$ \\
\hline Radicación con urbanización & 56 & $8,5 \%$ & 2631 & $9,6 \%$ \\
\hline Relocalización & 265 & $40,5 \%$ & 6655 & $24,4 \%$ \\
\hline Campamentos vigentes & 294 & $44,9 \%$ & 15887 & $58,2 \%$ \\
\hline Total campamentos catastrados & 655 & $100,0 \%$ & 27297 & 100
\end{tabular}

* Se excluyen asentamientos catastrados, pero que no cumplen con la definición de campamento

Fuente: Catastro Nacional de Campamentos 2011 (actualización enero 2018).

Tal como se señaló, las diferentes estrategias de intervención se ven ligadas a las posibilidades de integración de los campamentos, las cuales estarán también condicionadas por aspectos como el tamaño, antigüedad, así como por el contexto urbano donde se localizan. Si bien no es posible establecer una conexión directa entre estas características y el potencial de integración, es importante tener en cuenta de qué forma se relacionan con las diferentes estrategias adoptadas y la capacidad del programa de gestionar efectivamente los cierres. La Tabla 2 muestra el porcentaje de campamentos vigentes y cerrados (diferenciados por estrategia) según el tipo de ciudad, cantidad de familias y antigüedad.
La primera consideración tiene relación al tipo de ciudad. Se observa que los campamentos de áreas metropolitanas, con un $41 \%$ de cierres, tienen un porcentaje de cierre muy bajo en comparación a las otras ciudades. Es probable que esto tenga relación y de cuenta de las dificultades asociadas a la gestión del suelo en las áreas urbanas de mayor escala. Además, si bien las estrategias de relocalización son las más frecuentes en todos los tipos de ciudad, en las áreas metropolitanas las estrategias de radicación parecen ser aún menos factibles, presentando un porcentaje de cierre de casi la mitad respecto a la categoría de ciudades que le sigue. 
En cuanto a la cantidad de familias residentes en los campamentos, la tasa de cierre es mucho mayor en los que tienen una menor cantidad de familias, alcanzando un 63\% en los asentamientos más pequeños, mientras que solo alcanza un $42 \%$ en los que tienen más de cien. Por otra parte, dependiendo del tamaño de los campamentos existen diferencias importantes respecto a las estrategias adoptadas. La estrategia de relocalización ha sido más aplicada en el caso de campamentos de menor tamaño, mientras que las estrategias de radicación son más frecuentes en la medida en que la cantidad de familias en los campamentos es mayor.

Respecto a la antigüedad, resulta llamativo que los campamentos más proclives a ser cerrados han sido los más nuevos, con menos de 10 años de antigüedad. La mayoría de ellos se ha cerrado a través de la estrategia de relocalización. En la medida en que la antigüedad de los campamentos es mayor, su intervención ha sido menos frecuente, y algo más proclive a los proyectos de urbanización, que tiene un peak en los campamentos de entre 10 y 20 años y luego un declive.

En definitiva, en función de los datos presentados, es posible hipotetizar que, de modo general, son los campamentos de mayor tamaño y más antigüedad, ubicados en áreas metropolitanas, los que presentarían mayores dificultades para ser intervenidos por el programa. De esta manera, los desafíos de integración están en primera instancia mediados por esta diferencia, que mantiene vigentes a cerca de la mitad de los campamentos catastrados en 2011.

Por otra parte, pese a la implementación del Programa de Campamentos, entre 2011 y 2018, la cantidad de campamentos y, especialmente, la cantidad de familias viviendo en ellos, aumentó considerablemente. Si bien en este mismo período se declararon 361 campamentos como cerrados, en el nuevo catastro se han registrado al menos 489 campamentos que no habían sido contabilizados anteriormente, y que permanecieron fuera del ámbito de acción del programa durante ese período. Es decir, por cada tres campamentos cerrados, surgieron otros cuatro. Ello da cuenta de las dificultades del programa para hacer frente a un problema que parece ser estructural. Este aumento se produce con mayor intensidad en las regiones del norte (Tarapacá, Antofagasta y Atacama), aunque también es relevante el crecimiento que se observa en la región de Valparaíso, que continúa siendo la que tiene mayor cantidad de asentamientos de este tipo.

Las particularidades económicas y territoriales de las ciudades son relevantes para comprender el crecimiento de los campamentos, así como también para pensar en sus posibilidades de integración social. El crecimiento de las ciudades del norte está marcado por la actividad minera, que produce aumentos en los precios del suelo y a la 


\section{TABLA 2. PORCENTAJE DE CIERRE Y ESTRATEGIAS DE CIERRE DE CAMPAMENTOS CATASTRADOS EN CATASTRO NACIONAL DE CAMPAMENTOS 2011, SEGÚN TIPO DE CIUDAD, CANTIDAD DE FAMILIAS POR CAMPAMENTO Y ANTIGÜEDAD DEL CAMPAMENTO.}

\begin{tabular}{|c|c|c|c|c|c|c|c|}
\hline & & \multicolumn{4}{|c|}{ Campamentos Cerrados } & \multirow{2}{*}{$\begin{array}{l}\text { Campamentos } \\
\text { vigentes }\end{array}$} & \multirow{2}{*}{$\begin{array}{l}\text { Total general } \\
\text { (Nro.) }\end{array}$} \\
\hline & & $\begin{array}{l}\text { Radica- } \\
\text { ción con } \\
\text { urbanización }\end{array}$ & $\begin{array}{l}\text { Radica- } \\
\text { ción CNT } \\
\text { (proyecto } \\
\text { habitacional) }\end{array}$ & Relocalización & $\begin{array}{l}\text { Total cam- } \\
\text { pamentos } \\
\text { cerrados }\end{array}$ & & \\
\hline \multirow[t]{4}{*}{$\begin{array}{l}\text { Tipo de } \\
\text { ciudad }\end{array}$} & $\begin{array}{l}\text { Menos de } 50 \mathrm{mil} \\
\text { habitantes }\end{array}$ & $13 \%$ & $5 \%$ & $53 \%$ & $72 \%$ & $28 \%$ & $100 \%(166)$ \\
\hline & $\begin{array}{l}\text { Entre } 50 \text { mil y } 200 \\
\text { mil habitantes }\end{array}$ & $12 \%$ & $8 \%$ & $45 \%$ & $65 \%$ & $35 \%$ & $100 \%(86)$ \\
\hline & $\begin{array}{l}\text { Entre } 200 \text { mil y } \\
500 \text { mil habitantes }\end{array}$ & $11 \%$ & $13 \%$ & $42 \%$ & $66 \%$ & $34 \%$ & $100 \%(85)$ \\
\hline & $\begin{array}{l}\text { Áreas } \\
\text { Metropolitanas }\end{array}$ & $5 \%$ & $4 \%$ & $32 \%$ & $41 \%$ & $59 \%$ & $100 \%(318)$ \\
\hline \multirow{4}{*}{$\begin{array}{l}\text { Canti- } \\
\text { dad de } \\
\text { familias }\end{array}$} & Menos de 25 & $6 \%$ & $5 \%$ & $52 \%$ & $63 \%$ & $37 \%$ & $100 \%(342)$ \\
\hline & Entre 25 y 49 & $10 \%$ & $5 \%$ & $38 \%$ & $53 \%$ & $47 \%$ & $100 \%(172)$ \\
\hline & Entre 50 y 99 & $11 \%$ & $9 \%$ & $17 \%$ & $37 \%$ & $63 \%$ & $100 \%(93)$ \\
\hline & Más de 100 & $15 \%$ & $13 \%$ & $15 \%$ & $42 \%$ & $58 \%$ & $100 \%(48)$ \\
\hline \multirow{5}{*}{$\begin{array}{l}\text { Antigüe- } \\
\text { dad del } \\
\text { campa- } \\
\text { mento }\end{array}$} & 10 años o menos & $2 \%$ & $19 \%$ & $67 \%$ & $88 \%$ & $13 \%$ & $100 \%(48)$ \\
\hline & Entre 11 y 20 años & $11 \%$ & $8 \%$ & $39 \%$ & $58 \%$ & $42 \%$ & $100 \%(221)$ \\
\hline & Entre 21 y 30 años & $8 \%$ & $4 \%$ & $40 \%$ & $51 \%$ & $49 \%$ & $100 \%(186)$ \\
\hline & 31 años o más & $8 \%$ & $4 \%$ & $33 \%$ & $45 \%$ & $55 \%$ & $100 \%(191)$ \\
\hline & Sin dato & $0 \%$ & $0 \%$ & $100 \%$ & $100 \%$ & $0 \%$ & $100 \%(9)$ \\
\hline \multicolumn{2}{|c|}{ Total general } & $9 \%$ & $6 \%$ & $40 \%$ & $55 \%$ & $45 \%$ & $100 \%(655)$ \\
\hline
\end{tabular}

Fuente: Catastro Nacional de Campamentos 2011 (actualización enero 2018) 
vez atrae a población migrante que se inserta de manera precaria en la economía local. En el Gran Valparaíso, el crecimiento urbano informal hacia la periferia se ve favorecido por las condiciones geográficas, marcadas por la presencia de laderas de cerro y quebradas que difícilmente pueden ser urbanizadas. En el centro-sur y sur del país, las áreas periféricas de las ciudades asumen una condición semi-rural, asociada a la actividad agrícola de carácter estacional. Finalmente, si bien en el caso de Santiago los campamentos tienen una presencia menor, el crecimiento sostenido de los precios y la búsqueda por una mejor localización empujan también a la llegada de más familias a los campamentos. En el siguiente apartado se desarrolla un análisis de cuatro casos representativos de estos distintos escenarios.

\section{ANÁLISIS CUALITATIVO DE CASOS}

La definición de la muestra de casos de estudios en cada región, se estableció a partir de criterios territoriales que permitieron considerar la máxima diversidad de tipologías desplegadas por el Programa de Campamentos a nivel del país, seleccionándose los casos detallados en la Tabla 3.

La estrategia metodológica planteó el desarrollo de 34 entrevistas semi-estructuradas con pobladores de nuevos conjuntos de vivienda dirigidos a familias de provenientes de campamentos. Estas tienen como fin, abordar la experiencia de pobladores radicados y/o relocalizados, tanto pertenecientes como no pertenecientes a campamentos, para cubrir la realidad de los casos regionales donde se crearon urbanizaciones mixtas. Se incorporaron también cuatro entrevistas, una con cada encargado regional del Programa de Campamentos. Adicionalmente se desarrollaron cuatro grupos focales, uno por locación, con residentes de los nuevos conjuntos provenientes de campamentos y cuatro recorridos y mapeos participativos por proyecto residencial.

Siguiendo lo anterior, la muestra definitiva quedó determinada de la forma indicada en la Tabla 4.

Una caracterización general de los casos, plantea que se trata de proyectos de vivienda entregados durante los últimos siete años, siendo el más reciente el proyecto la Villa Estrellita de Copiapó en 2018. A este le siguen el conjunto Villa Humboldt de Quilpué en 2017, siendo los más antiguos los proyectos Nueva Las Torres de San Francisco de Mostazal de 2015 y Villa Jardines de Velásquez/ Renacer por un Sueño, entregado el año 2013.

En el caso de Villa La Estrellita (Figura 1) se trata de una intervención de viviendas independientes pareadas de una planta, que albergan a 35 familias provenientes de un campamento asentado en el mismo sector en 2003, siendo mayoritariamente conformado por mujeres jefas de hogar y sus hijos, quienes conforman el comité de vivienda homónimo en 2011. 
TABLA 3. CUADRO RESUMEN CASO DE ESTUDIO POR REGIÓN Y TIPOLOGÍA

\begin{tabular}{|c|c|c|c|c|c|}
\hline $\begin{array}{l}\text { Caso: proyecto } \\
\text { habitacional }\end{array}$ & Región & Tipo de ciudad & $\begin{array}{l}\text { Tipología de } \\
\text { estrategia programa }\end{array}$ & $\begin{array}{l}\text { Cantidad de } \\
\text { familias }\end{array}$ & $\begin{array}{l}\text { Contexto histórico y escala } \\
\text { del campamento }\end{array}$ \\
\hline Villa La Estrellita & Atacama & $\begin{array}{l}\text { Copiapó, ciudad } \\
\text { asociada a la } \\
\text { minería } \\
\text { Entre } 50 \text { mil y } 200 \\
\text { mil habitantes }\end{array}$ & $\begin{array}{l}\text { Radicación con Pro- } \\
\text { yecto Habitacional. } \\
100 \% \text { familias de } \\
\text { campamento }\end{array}$ & Entre 25 y 49 & $\begin{array}{l}\text { Familias provenientes de } \\
\text { Campamento La Estrellita, } \\
\text { formado a comienzos del } \\
\text { 2000. Comité de vivienda se } \\
\text { constituye en } 2011 .\end{array}$ \\
\hline $\begin{array}{l}\text { Villa Altos de } \\
\text { Humboldt }\end{array}$ & Valparaíso & $\begin{array}{l}\text { Quilpué, comuna } \\
\text { del interior del } \\
\text { Área } \\
\text { Metropolitana } \\
\text { de Valparaíso }\end{array}$ & $\begin{array}{l}\text { Relocalización } \\
57 \% \text { familias de } \\
\text { campamentos }\end{array}$ & Entre 50 y 99 & $\begin{array}{l}\text { Familias provenientes de } \\
\text { campamento Los Funda- } \\
\text { dores, formado en } 2000 . \\
\text { Comité de vivienda defini- } \\
\text { tivo se crea en } 2009 .\end{array}$ \\
\hline $\begin{array}{l}\text { Villa Jardines } \\
\text { de Velásquez/ } \\
\text { Renacer por un } \\
\text { sueño }\end{array}$ & Metropolitana & $\begin{array}{l}\text { Lo Espejo, comu- } \\
\text { na de sectores } \\
\text { populares, parte } \\
\text { del } \\
\text { Área } \\
\text { Metropolitana } \\
\text { de Santiago }\end{array}$ & $\begin{array}{l}\text { Relocalización } \\
36 \% \text { familias de } \\
\text { campamento }\end{array}$ & Más de 100 & $\begin{array}{l}\text { Familias provenientes de } \\
\text { campamentos históricos } \\
\text { como Luxemburgo y Las } \\
\text { Turbinas de más de } 30 \text { años } \\
\text { de antigüedad. } \\
\text { Proceso de postulación y } \\
\text { organización de comités } \\
\text { comienza en } 2008 .\end{array}$ \\
\hline $\begin{array}{l}\text { Villa Nueva las } \\
\text { Torres }\end{array}$ & O'Higgins & $\begin{array}{l}\text { San Francisco de } \\
\text { Mostazal, ciudad } \\
\text { vinculada al } \\
\text { mundo agrícola } \\
\text { temporero. } \\
\text { Menos de } 50 \text { mil } \\
\text { habitantes }\end{array}$ & $\begin{array}{l}\text { Relocalización } \\
100 \% \text { familias de } \\
\text { campamento }\end{array}$ & Entre 25 y 49 & $\begin{array}{l}\text { Familias provenientes cam- } \\
\text { pamento Las Torres, de más } \\
\text { de } 30 \text { años de antigüedad. } \\
\text { Se suman familias del cam- } \\
\text { pamento El Cupio. } \\
\text { Se organizan como comité } \\
\text { definitivo en } 2012 \text {. }\end{array}$ \\
\hline
\end{tabular}

Fuente: Elaboración propia 
TABLA 4. CUADRO RESUMEN CASOS Y TÉCNICAS DE LEVANTAMIENTO INFORMACIÓN PRIMARIA

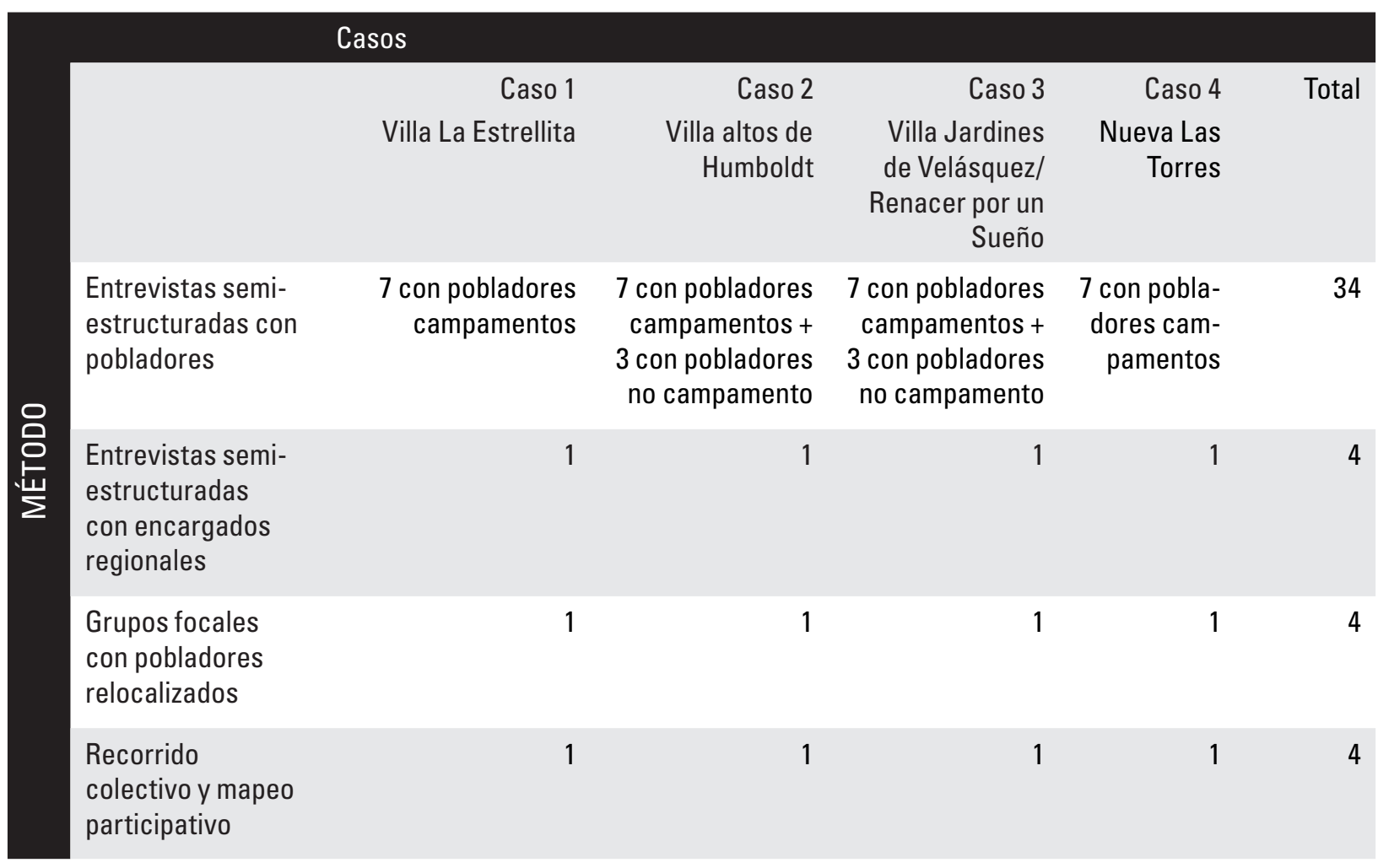

Fuente: Elaboración propia 
FIGURA 1. PROYECTO DE RADICACIÓN VILLA LA ESTRELLITA EN COPIAPÓ.

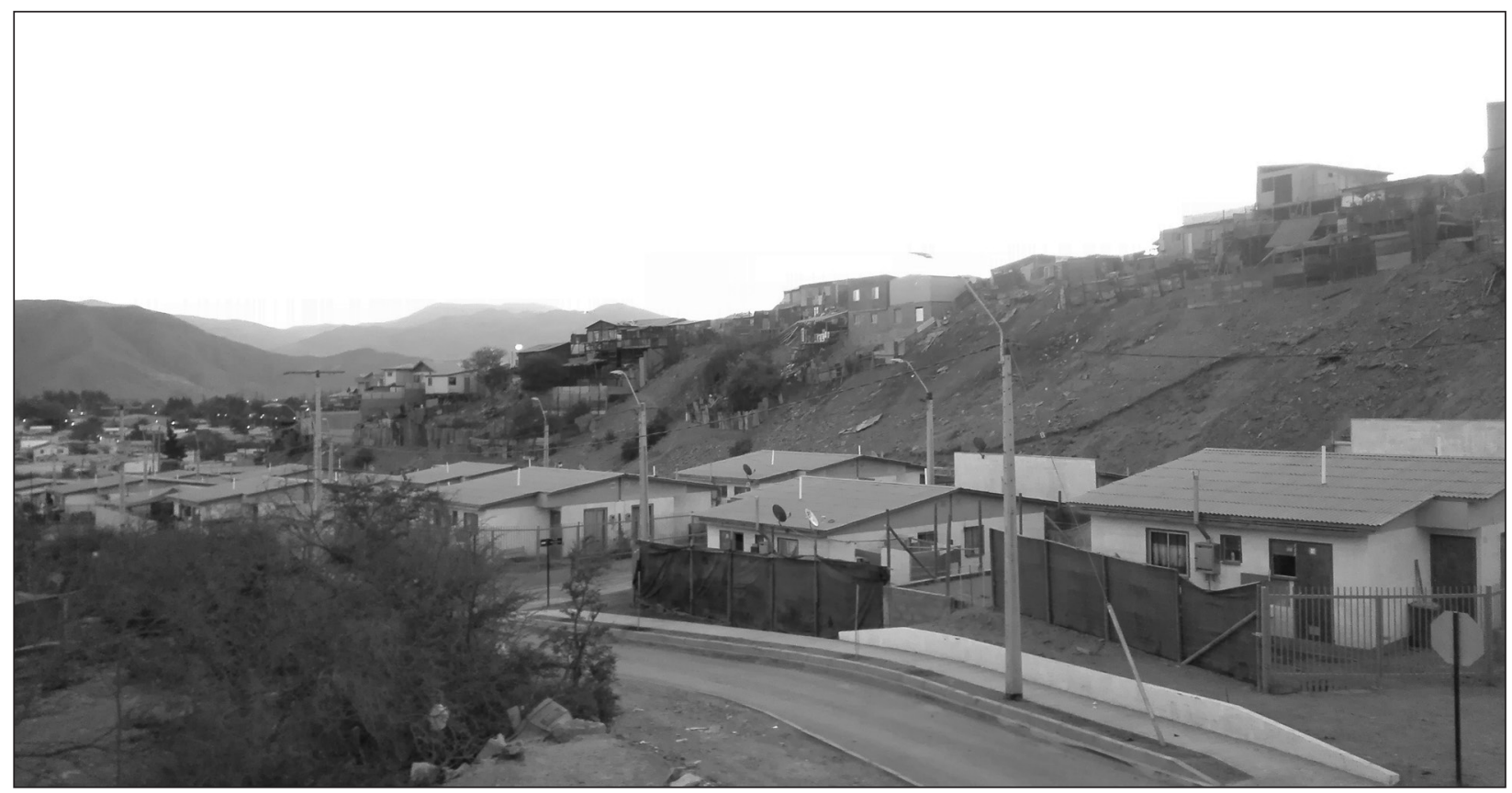

Fuente: elaboración propia

FIGURA 2. VILLA HUMBOLDT EN QUILPUÉ.

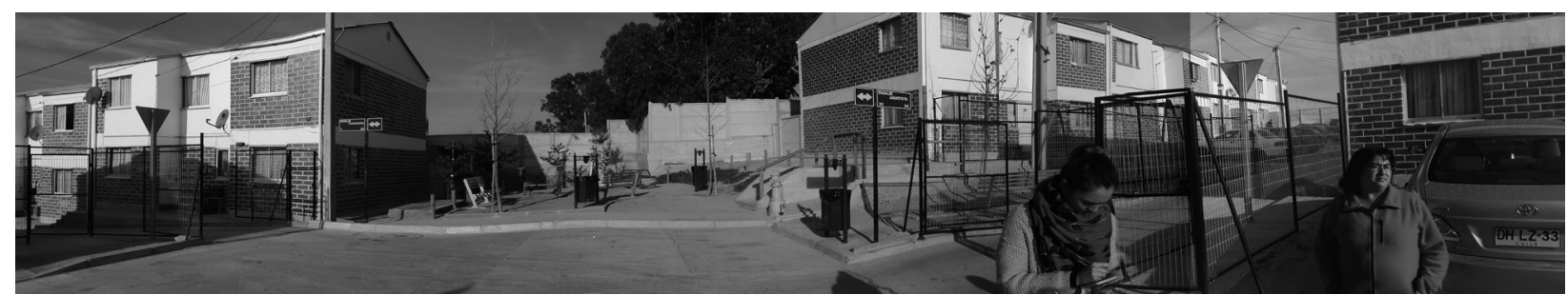

Fuente: elaboración propia 


\section{FIGURA 3. VILLA NUEVA LAS TORRES.}

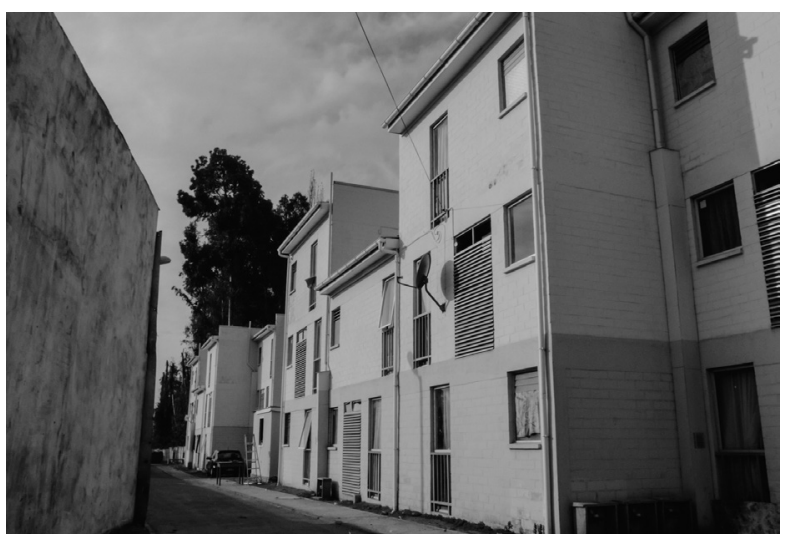

Fuente: elaboración propia

En el caso de Villa Humboldt (Figura 2) se trata de un conjunto de vivienda que incluye a 54 familias, provenientes mayoritariamente del Campamento Luchando por un Sueño, y 22 familias postulantes regulares a subsidio de vivienda.

En el caso de Nueva Las Torres (Figura 3), se trata de un conjunto que alberga a 28 familias, de las cuales 24 provenían del campamento Las Torres ubicado desde fines de los años ochenta en el terreno de la estación de trenes de la localidad, perteneciente a EFE, y un grupo minoritario de cuatro familias del Campamento Cumpío. Ambos grupos componen un comité de vivienda que se crea en 2011.
Finalmente, el caso más complejo es Villa Jardines de Velásquez/Renacer por un Sueño (Figura 4), conjunto de vivienda que agrupa a un total de 149 viviendas que consideran tres tipologías distintas: dos de viviendas pareadas independientes y una de bloques construido en dos fases, primero Renacer por un Sueño cuya entrega se hace en 2012 y finalmente Jardines de Velásquez entregada en 2013, después de un período de postulación que se abre en 2008 con la conformación de los respectivos comités de vivienda.

A continuación, desarrollaremos un análisis centrado en la reconstrucción del proceso de integración de las familias de campamentos a sus nuevos conjuntos de vivienda y barrios, contrastando las experiencias abordadas en terreno de radicación y relocalización. Para ello, se consideran las dimensiones de apego y afecto, sentido de comunidad y participación, que fueron definidas anteriormente.

La comparación entre los diferentes casos nos permitió establecer la existencia, en el proyecto de radicación en Villa La Estrellita de Copiapó, de una fuerte articulación entre los componentes de apego y afecto territorial, sentido de comunidad y capacidad de participar y gestionar el territorio. Una interrelación sinérgica entre estos elementos no se da en los casos de relocalización, destacando que se dificulta la construcción de un sentido de comunidad en los casos más complejos, que articulan 
experiencias mixtas de creación de barrios, que mezclan familias de campamentos con postulantes individuales a subsidio. A partir de esta mezcla se generan tendencias de auto-segregación en sectores diferenciados, en que se concentran pobladores de campamentos y otros de familias que acceden vía subsidio individual. El caso más patente lo plantea la intervención de Lo Espejo, que cuenta con una mayor cantidad de familias que no provienen de campamentos.

De la misma forma, las relocalizaciones comparten una tendencia a incorporar una satisfacción residencial que, si bien genera apego y arraigo a las viviendas, no se expresa en un sentido de barrio, que implique un trabajo conjunto por mejoras comunitarias a sus espacios públicos ni el desarrollo de capacidades colectivas de administrar los conjuntos. En los casos que reúnen familias de campamentos con otras de distintos orígenes, se pudo constatar la confusión de los vecinos respecto a cómo gestionar en forma colectiva el conjunto como un espacio de co-propiedad.

Al analizar el proceso previo de participación en cada conjunto encontramos que, en el caso de radicación, la participación se da fundamentalmente entre familias que ya se conocen, que tiene una historia común, que comparten vínculos y que han comenzado el proceso de postulación a sus viviendas en mutuo acuerdo. Por el contrario, la participación que existe en instancias de relocalización tiene como base el desconocimiento del nuevo territorio, lo cual ya genera un proceso de desafección con el lugar que han habitado, a lo que se suma el hecho de que las familias tienen que comenzar a generar nuevas relaciones con las personas que no provienen de campamentos con las que van a cohabitar.

El análisis comparativo permitió relevar que cuando existe un sentido de comunidad previo, el proceso de participación tiende a realizarse a partir de metas compartidas, lo cual genera una base para que la participación culmine en la construcción exitosa de un nuevo barrio.

Sin embargo, las dinámicas de relación internas dentro de los nuevos barrios, una vez instaladas las familias en los condominios, dan cuenta de que la participación previa a la llegada al conjunto habitacional no ha logrado revertir la situación de segregación que se produce entre los grupos de postulantes, perpetuándose esta incluso a nivel de divisiones territoriales dentro de los conjuntos habitacionales.

Una de las instancias claves que se dan dentro del proceso de participación, tiene relación con los liderazgos y formas de organizar y gestionar tanto los nuevos conjuntos como la comunidad residente. Esto repercutirá directamente en la integración, puesto que quedó en evidencia a partir de los casos estudiados, que la forma en que se organiza el conjunto habitacional guarda relación con cómo se 


\section{FIGURA 4. VILLA JARDINES DE VELÁSQUEZ/ RENACER POR UN SUEÑO.}

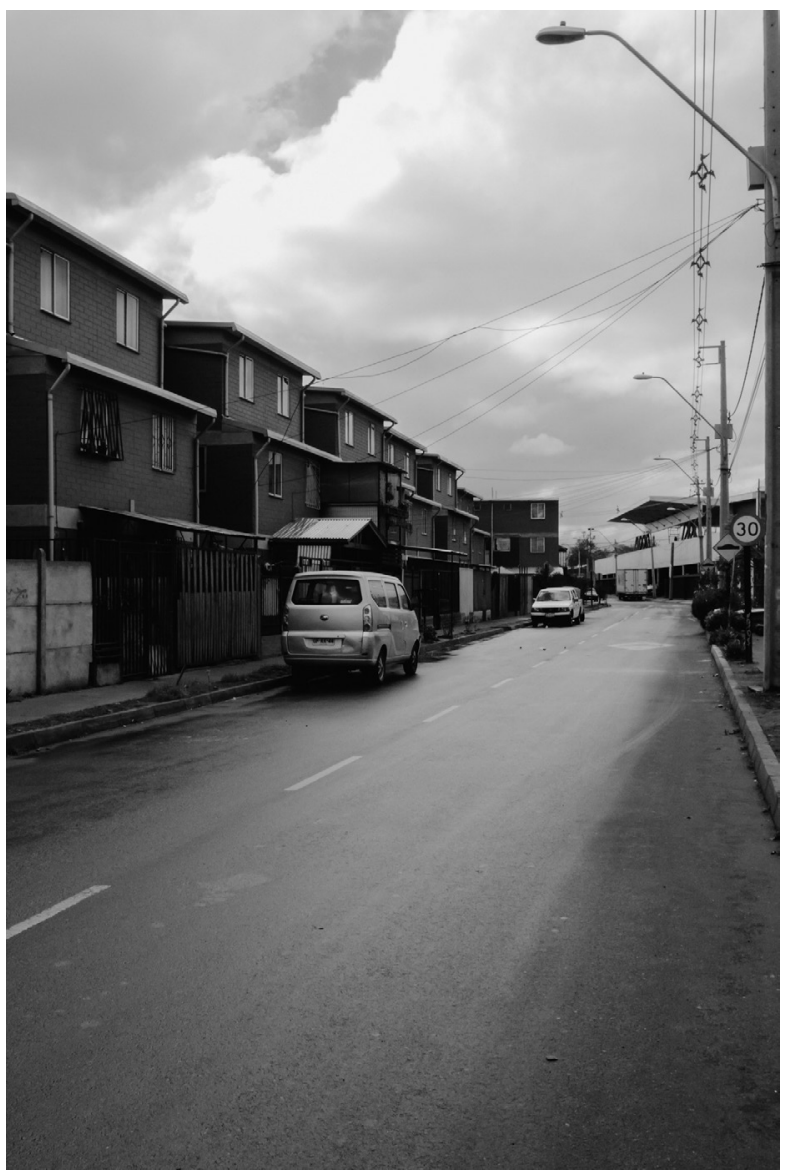

Fuente: elaboración propia estructuran las relaciones sociales al interior del nuevo barrio. Si el proceso no logra establecer liderazgos claros y formas de organización y administración que sean consideradas como justas y eficientes por el grueso de la comunidad, es probable que se generen rencillas, desinformación, desconfianza, etc., provocando que la posibilidad de integración baje sustancialmente. En contraste, como plantea la experiencia de La Estrellita de Copiapó, en los procesos de radicación es probable que los liderazgos se mantengan, o al menos se pueda llegar a una decisión común respecto a qué hacer con los liderazgos existentes y en el peor de los casos a consensuar una manera en que se pueda elegir los nuevos líderes o administración. Por el contrario, en el proceso de relocalización se ha podido observar que existe una tendencia de las familias a velar por los propios intereses o los del grupo original de procedencia, dejando a los nuevos integrantes marginados respecto a información básica del funcionamiento de los conjuntos habitacionales, la toma de decisiones, consultas, posibilidades de participar en las instancias de participación, entre otros. Esta situación, agrava fuertemente la falta de integración que se produce al interior de estos lugares, viéndose afectados tanto los afectos sociales como espaciales, influyendo directamente en la posibilidad de conformación de sentido de comunidad. 
La conformación o no de un sentido de comunidad, afectará la posibilidad de uso y apropiación de los espacios públicos y equipamientos. La satisfacción residencial, comprendida no solo como la consideración de la satisfacción con la vivienda, sino en un amplio sentido (satisfacción con el territorio, con los vecinos, con los implementos o equipamientos que ofrece el conjunto habitacional), es uno de los puntos en que es posible notar que el grado de sentido de comunidad, así como su consecuente apego e identidad espacial, repercute en cuestiones como la valoración y utilización de los espacios comunes y equipamiento. El caso más claro de esto, es el de Lo Espejo, que a pesar de que tiene buenos espacios comunes e implementos, no son utilizados por las familias integrantes de la comunidad, en una clara demostración de que la integración y el sentido de comunidad no están funcionando.

\section{Conclusiones: reflexiones y recomendaciones para el abordaje de la integración social en campamentos}

A través de este trabajo, se releva la importancia de incorporar la temática de los asentamientos informales y su inserción en las ciudades, en el contexto más amplio de discusión sobre integración social. La consideración de las dimensiones cualitativas del afecto y apego, sentido de comunidad y participación al estudio de la integración social permite complementar las definiciones más estáticas del concepto, proponiendo una aproximación para el estudio de los mecanismos específicos a través de los cuales se puede propiciar la integración en el contexto de los barrios post-campamento.

Los resultados presentados permitieron evidenciar algunos de los principales desafíos de integración social para los asentamientos informales, a través del Programa de Campamentos. En primer lugar, se observa que los campamentos más antiguos y con mayor cantidad de familias han sido los que el programa ha atendido con menor éxito, especialmente en aquellos que se localizan en áreas metropolitanas. En los casos de cierre, la estrategia más común ha sido la de relocalización, lo que contrasta con la anterior experiencia de Chile-Barrio, donde la mayoría de los campamentos fueron radicados (Ministerio de Hacienda, Dirección de Presupuestos, 2007). Por otra parte, a través del análisis de cuatro casos de campamentos atendidos por el programa, se pudo observar que los procesos de relocalización presentan mayores desafíos de integración social en términos de apego, participación y sentido de comunidad.

El importante incremento en la cantidad de familias que viven en campamentos muestra que existen 
mecanismos de exclusión de la vivienda formal en Chile, que afectan a una proporción creciente de la población. Por un lado, el crecimiento sostenido en los precios de las viviendas excluye a la mayoría de la posibilidad de acceder a una vivienda a través del mercado; por otro lado, la oferta de subsidios habitacionales desde el Estado no es capaz de absorber los nuevos requerimientos de sus potenciales beneficiarios, que no solo aspiran acceder a la vivienda como un bien individual, sino que a vivir en un barrio conectado e integrado a una red de servicios y bienes urbanos públicos en el contexto de una ciudad que tiende persistentemente a recrear nuevas formas de exclusión.

En este contexto, el estudio permite sostener que las acciones del Programa de Campamentos son limitadas para abordar el desafío de la integración, al buscar paliar una condición inicial de exclusión a través de estrategias que terminan restringiéndose a la provisión de vivienda de mayor calidad, no considerando un esfuerzo mayor y más integral de reconocimiento hacia elementos propios de la subjetividad del campamento, que forman parte de su construcción social del hábitat. Al respecto, la incorporación de las dimensiones cualitativas del afecto y apego, sentido de comunidad y participación al abordaje de los asentamientos informales en nuestro país, permitirían abrir mejores perspectivas para propiciar la integración social en todas las etapas de un proceso que no concluye, sino que se inicia con la conformación de nuevos barrios. En ese marco cabría incorporar ciertos énfasis distintivos en cada estrategia para propiciar mayor integración social.

En el caso de los proyectos de radicación, la tarea estaría más avanzada, como plantea el estudio de casos, cuando se establece un sentido de continuidad con el apego y arraigo y sentido del lugar, lo que sumado a potenciar el sentido de comunidad previo y la capacidad de participación de los pobladores aportaría bases para un proceso más integral, donde el desafío está en potenciar la agencia de los pobladores como constructores de ciudad. En el caso de las relocalizaciones, sobre todo las de proyectos de mayor escala insertos en dinámicas metropolitanas, el desafío sería más complejo al estar ausentes las dimensiones del apego, arraigo y sentido de comunidad, propiciando una baja participación y una auto-segregación en subgrupos dentro de los nuevos vecindarios.

Sería deseable que la actual política respecto a los asentamientos informales retomara un enfoque más amplio de abordaje de la integración a escala barrial y urbana, ya anticipado en parte en Chile Barrio, y ampliamente avalado por experiencias internacionales exitosas como Favela Bairro (Andreatta, 2005) y Morar Carioca (Marques, 2013) en Río de Janeiro, Serra do Mar (Perivier et ál., 2016); y Rosario Hábitat (Rosestein, 2008) entre otras, que muestran la importancia de impulsar intervenciones participativas no limitadas a la entrega de vivienda como bien individual a 
familias beneficiarias sino con objetivos más amplios e integrales de potenciamiento de nuevos barrios en donde sus residentes son protagonistas de la gestión de un territorio que sienten propio. En consonancia con la revisión de experiencias internacionales, el desafío de abordar la integración post-campamento pasa por habilitar al sujeto de intervención, para que se haga cargo en forma autónoma, de gestionar en el mediano y largo plazo, la convivencia en copropiedad, desarrollando habilidades y conocimientos prácticos para resolver conflictos y construir normas compartidas de convivencia. Para ello es importante incorporar un enfoque de empoderamiento desde el inicio de la intervención, cuyas acciones promuevan entre los habitantes una visión de sí mismos no solo como beneficiarios individuales, sino como ciudadanos y vecinos, con derechos y deberes en relación a sus viviendas y conjuntos.

La profundización de este aspecto puede aportar en una vinculación más efectiva del Programa, con los nuevos desafíos en cuanto a las políticas de integración social, contribuyendo a revertir el predominio de lógicas individualistas y segregadoras.

\section{Referencias bibliográficas}

Abramo, P. (2012). La ciudad com-fusa: Mercado y producción de la estructura urbana en las grandes metrópolis latinoamericanas. EURE, 38(114), 35-69. doi:10.4067/S0250-71612012000200002

Andreatta, V. (2005). Favela-bairro, un nuevo paradigma de urbanización para asentamientos informales. Cuadernos Internacionales de Tecnología para el Desarrollo Humano, (3).

Arnstein, S. (1969). A ladder of citizen participation. Journal of the American Institute of Planners, 35(4), 216-224. doi:10.1080/01944366908977225

Arriagada, C. y Morales, N. (2006). Ciudad y seguridad ciudadana en Chile: revisión del rol de la segregación sobre la exposición al delito en grandes urbes. Eure, 32(97), 37-48. doi:10.4067/ S0250-71612006000300003

Berroeta, H., Carvalho, L., Di Masso, A., y Ossul Vermehren, M. (2017). Apego al lugar: una aproximación psicoambiental a la vinculación afectiva con el entorno en procesos de reconstrucción del hábitat residencial. Revista INVI, 32(91), 113-139. doi:10.4067/S0718-83582017000300113

Berroeta, H., Ramoneda, A., y Opazo, L. (2015). Sentido de comunidad, participación y apego al lugar en comunidades desplazadas y no desplazadas post desastres: Chaitén y Constitución. Universitas Psychologica, 14(4), 15-27. doi:10.11144/Javeriana.upl4-4.scpa 
Brain, I., Prieto, J., y Sabatini, F. (2010). Vivir en campamentos: ¿camino hacia la vivienda formal o estrategia de localización para enfrentar la vulnerabilidad? EURE, 36(109), 11-141. doi:10.4067/ S0250-71612010000300005

Calderón, J. (2016). La ciudad ilegal. Lima en el siglo XX. Lima: Magreb Producciones.

Camargo, D. y Abiko, A. (2015) Evaluation slum (favela) resettlements: The case of the Serra do Mar Project, Sao Paulo, Brazil. Habitat International, 49, 340-348. doi:10.1016/j.habitatint.2015.05.014

Campos, L., Silva, R., y Gaete, M. (2017). El rol de las emociones y los afectos en la producción del hábitat y el territorio. Revista INVI, 32(91), 9-21. doi:10.4067/S0718-83582017000300009

Castells, M. (1973). Movimiento de pobladores y lucha de clases en Chile. EURE, 3(7), 9-35.

CIS-TECHO Chile. (2015). Datos duros de una realidad más dura: Encuesta nacional de campamentos 2015. Santiago: Autor.

Clichevsky, N. (2009). Algunas reflexiones sobre informalidad y regularización del suelo urbano. Bitácora Urbano Territorial, 14(1), 63-88. doi:10.15446/bitacora

Cortés, A. (2014). El movimiento de pobladores chilenos y la población La Victoria: ejemplaridad, movimientos sociales y derecho a la ciudad. EURE, 40(119), 239-260. doi:10.4067/ S0250-71612014000100011

Di Masso, A. y Dixon, J. (2015). More than words: place attachment and struggle over public space in
Barcelona. Qualitative Research in Psychology, 12(1), 45-60. doi:10.1080/14780887.2014.958387

Di Virgilio, M. M. (2015). Urbanizaciones de origen informal en Buenos Aires. Lógicas de producción de suelo urbano y acceso a la vivienda. Estudios Demográficos y Urbanos, 30(3), 651-690.

Domínguez, P. (2011). Campamentos, viviendas y acceso a la ciudad para los pobres. Revista CIS, (14) 73-94.

Equipo de Estudios Poblacionales (CIDU). (1972). Reivindicación urbana y lucha política: los campamentos de pobladores en Santiago de Chile. EURE, 2(6), 55-82.

Espinoza, V. (1998). Historia social de la acción colectiva urbana: Los pobladores de Santiago, 1957-1987. EURE, 24(72), 71-84. doi:10.4067/ S0250-71611998007200004

Fernandes, E. (2011). Regularization of informal settlements in Latin America. Cambridge: Lincoln Institute of Land Policy.

Fullilove, M. (1996). Psychiatric implications of displacement: Contributions from the psychology of place. The American Journal of Psychiatry, 53(12), 1516-1523. doi:10.1176/ajp.153.12.1516

Galster, G. y Killen, S. (1995). The geography of metropolitan opportunity: a reconnaissance and conceptual framework. Housing Policy Debate, 6(1), 7-43. doi:10.1080/10511482.1995.9521180

Garcés, M. (2002). Tomando su sitio. El movimiento de pobladores de Santiago, 1957-1970. Santiago: de Chile: LOM. 
Garcés, M. (2017). Los pobladores y la política en los años ochenta: reconstrucción de tejido social y protestas nacionales. Revista Historia 396, 7,(1).

Greene, M. y Cortés, S. (2018). Asentamientos Informales. En CEDEUS (Ed.), Camino a ciudades sustentables. Aportes desde la investigación a las políticas urbanas en Chile (pp. 121-125). Santiago: UC.

Hernández, B., Hidalgo, M., Salazar-Laplace, M., y Hess, S. (2007). Place attachment and place identity in natives and non-natives. Journal of Environmental Psychology, 27(4), 310-319. doi:10.1016/j. jenvp.2007.06.003

Hidalgo, M., y Hernández, B. (2001). Place attachment: Conceptual and empirical questions. Journal of Environmental Psychology, 21(3), 273-281. doi:10.1006/jevp.2001.0221

Jaramillo, S. (2008). Reflexiones sobre la "informalidad" fundiaria como peculiaridad de los mercados del suelo en las ciudades de América Latina. Territorios, (18/19), 11-53.

Kaztman, R. (2001). Seducidos y abandonados: el aislamiento social de los pobres urbanos. Revista de la CEPAL, 75, 171-189.

Kaztman, R. (2010). La dimensión espacial de la cohesión social en América Latina. En J. C. Feres y P. Villatoro (Eds.), Cohesión social en América Latina (pp. 39-84). Santiago: CEPAL.

Lewicka, M. (2011). Place attachment: How far have we come in the last 40 years? Journal of Environmental Psychology, 31(3), 207-230. doi:10.1016/j. jenvp.2010.10.001
Lombard, M. (2015). Lugarización y la construcción de asentamientos informales en México. Revista INVI, 30(83), 117-146. doi:10.4067/ S0718-83582015000100004

Long, D. y Perkins, D. (2003). Confirmatory factor analysis of the sense of community index and development of a brief SCI. Journal of Community Psychology, 3, 279-296. doi:https://doi.org/10.1002/ jcop. 10046

López-Morales, E., Flores Pineda, P., y Orozco Ramos, H. (2018). Inmigrantes en campamentos en Chile: ¿mecanismo de integración o efecto de exclusión? Revista INVI, 33(94), 159-185. doi:10.4067/ S0718-83582018000300161

Marques, M. (2013). Vivienda, favela y futuro. Mejoría en viviendas en favelas después de la metodología "favela-bairro". El caso Santa Marta. Cuadernos de Vivienda y Urbanismo, (separata). Recuperado de https://revistas.javeriana.edu.co/index.php/cvyu/ article/view/5920

Massey, D. y Denton, N. (1993). American apartheid. Cambridge: Harvard University Press.

Matus, C. (2017). Planificación participativa y urbanismo popular. Usos de la memoria, la identidad y el patrimonio en poblaciones históricas de Santiago y Concepción. Revista Planeo, (51).

McMillan, D. y Chavis, D. (1986). Sense of community: A definition and theory. Journal of Community Psychology, 14(1), 6-23. doi:10.1002/1520-6629(198601)14:1<6::AIDJCOP2290140103>3.0.CO;2-I 
Ministerio de Hacienda, Dirección de Presupuestos. (2007). Minuta ejecutiva evaluación Programa Chile Barrio, Ministerio de Vivienda y Urbanismo. Santiago: Autor.

Ministerio de Vivienda y Urbanismo (MINVU). (2010). El Programa Chile Barrios, de medida de emergencia política pública. Santiago: Autor.

Ministerio de Vivienda y Urbanismo (MINVU). (2011). Informe catastro nacional de campamentos. Santiago: Autor.

Ministerio de Vivienda y Urbanismo (MINVU). (2013). Mapa social de campamentos 2011. Santiago: Autor.

Ministerio de Vivienda y Urbanismo (MINVU). (2018) Bases técnicas y administrativas licitación "La vida después del campamento" en las regiones de Atacama, Valparaíso, O'Higgins y Metropolitana. Santiago: Autor.

Morales, E., Levy, S., Aldunate, A. y Rojas, S. (1990). Erradicados en el régimen militar. Una evaluación de los beneficiarios. Santiago de Chile: FLACSO.

Ocampo, G. (2003). Urbanización por invasión. Conflicto urbano, clientelismo y resistencia en Córdoba, Colombia. Revista Colombiana de Antropología, (39), 237-272.

Ochsenius, F., Carman, M., Lekerman, V., y Wertheimer, M. (2016). Políticas hacia villas y casas tomadas de la ciudad de Buenos Aires: tensiones entre la inclusión y la exclusión. Revista INVI, 31(88), 193215. doi:10.4067/S0718-83582016000300007

ONU-Habitat. (2015). Issue paper on informal settlements. New York: Autor.
Participatory Slum Upgrading Programme (PSUP). (2016). Slum almanac 2015 2016. Tracking improvement in the lives of slum dwellers. Nairobi: Autor.

Pérez, M. (2017). "A new poblador is being born": Housing struggles in a gentrified area of Santiago. Latin American Perspectives, 44(3). doi:10.1177/0094582X16668318

Pérez Valecillos, T. (2009). Organización, participación y autogestión en la construcción del hábitat residencial: Mecanismos de superación de la pobreza en asentamientos urbanos precarios. Caso de estudio: municipio Maracaibo del estado Zulia, Venezuela. Revista INVI, 16(43), 63-75.

Perivier, H., Arrasate, M. I., Georgoulias, A., Killmer, A., Ramírez, M. C., Watkins, G., y Meller, H. (2016). Serra do Mar and Atlantic Forest Mosaics System Socio-Environmental Recovery Program, Brazil. New York: IDB.

Perkins, D. D., Florin P., Rich, R. C., y Wandersman, A. (1990). Participation and the social and physical environment of residential blocks: Crime and community context. American Journal of Community Psychology, 18(1), 83-115. doi:10.1007/ BF00922690

Pino, A. y Ojeda, G. (2013). Ciudad y hábitat informal: Las tomas de terreno y la autoconstrucción en las quebradas de Valparaíso. Revista INVI, 28(78), 109140. doi:10.4067/S0718-83582013000200004

Ramón, A. d. (1990). La población informal. Poblamiento de la periferia de Santiago de Chile 1920-1970. EURE, 16(50), 5-17. 
Ramoneda, A. y Jerez, P. (2018). Community, participation and urban transformation. En R. Krebs y M. Tomaselli (Eds.), Urban design lab handbook. Dialogue-oriented urban transformation processes and practical approaches from Latin America and the Caribbean. Germany: Jovis.

Rinus, P., Martiniello, M., Brey, E., Cachón, L., y Garcés, B. (2006). Procesos de integración y políticas (locales): estado de la cuestión y algunas enseñanzas. Integration processes and (local) policies: Status of the issue lessons to be learned)". Reis, (116), 123-56. doi:10.2307/40184810.

Rodríguez, A. y Sugranyes, A. (2005). Los con Techo. Un desafí para la política de vivienda social. Santiago: Ediciones SUR.

Romero, G. (2012). La producción social del hábitat. Reflexiones sobre su historia, concepciones y propuestas. En E. Ortiz y L. Zárate (Comps.), Vivitos y coleando: 40 años trabajando por el hábitat popular en América Latina. México: HIC América Latina, UAM.

Rosestein, C. (2008). El Programa Rosario Hábitat y la integración como factor de mejora en la calidad de vida. El caso del asentamiento "La Lagunita". Estudios del Hábitat, 10, 59-73.

Ruiz-Tagle, J. (2016). La persistencia de la segregación y la desigualdad en barrios socialmente diversos: Un estudio de caso en La Florida, Santiago. EURE, 42(125), 81-108. doi:10.4067/ S0250-71612016000100004

Ruiz-Tagle, J. y López, E. (2014). El estudio de la segregación residencial en Santiago de
Chile: revisión crítica de algunos problemas metodológicos y conceptuales. EURE, 40(119), 25-48. doi:10.4067/S0250-71612014000100002

Sabatini, F. (2000). Reforma de los mercados de suelo en Santiago, Chile: efectos sobre los precios de la tierra y la segregación residencial. EURE, 23(77), 49-80. doi:10.4067/S0250-71612000007700003

Sabatini, F., Cáceres, G., y Cerda, J. (2001). Segregación residencial en las principales ciudades chilenas: Tendencias de las últimas tres décadas y posibles cursos de acción. EURE, 27(82), 21-42. doi:10.4067/S0250-71612001008200002

Sabatini, F., Rasse, A., Mora, P., y Brain, I. (2012). ¿Es posible la integración en las ciudades chilenas? Disposición de los grupos medios y altos a la integración con grupos de extracción popular. EURE, 38(115), 159-194. doi:10.4067/ S0250-71612012000300008

Sabatini, F., Wormald, G., Sierralta, C., y Peters, P. (2008). Segregación residencial en Santiago: Tendencias 1992-2002 y efectos vinculados con su escala geográfica. En F. Sabatini (Ed.), Tendencias de la segregación en las principales ciudades chilenas (pp. 19-41). Santiago: PUC, INE.

Saez Giraldez, E., García Calderón, J., y Roch Peña, F. (2010). La ciudad desde la casa: ciudades espontáneas en Lima. Revista INVI, 25(70). doi:10.4067/ S0718-83582010000300003

Salcedo, R. y Rasse, A. (2017). La naturaleza heterogénea de las familias pobres urbanas. En T. Errazuriz y R. Greene (Eds.), Salcedo (pp. 83-107). Santiago: Bifurcaciones. 
Sarason, S. (1974). The psychological sense of community:Prospects for a community psychology. San Francisco: Jossey-Bass.

Scannell, L. y Gifford, R. (2010). Defining place attachment: A tripartite organizing framework. Journal of Environmental Psychology, 30(1), 1-10. doi:10.1016/j.jenvp.2009.09.006

Siclari, P. (2003). La participación en el Programa ChileBarrio: evaluación en curso y propuestas de mejoramiento. Revista INVI, 18(46), 71-95.

Skewes, J. C. (2005). De invasor a deudor: el éxodo desde los campamentos a las viviendas sociales en Chile. En A. Rodríguez y A. Sugranyes (Eds.), Los con techo. Un desafío para la politica de vivienda social (2a ed., pp. 103-124). Santiago: SUR.

Theodore, N., Peck, J., y Brenner, N. (2009). Urbanismo neoliberal: la ciudad y el imperio de los mercados. Temas Sociales, (66).

Tuan, Y. (2005). Cosmos y hogar. Un punto de vista cosmopolita. Barcelona, España: Melusina.

Turner, J. (1977). Vivienda, todo el poder para los usuarios. Madrid, España: Hermann Blume.

Vargas D., I., Jiménez M., E., Grindlay M., A., y Torres T., C. (2010). Procesos de mejoramiento barrial participativo en asentamientos informales: propuestas de integración en la ciudad de Ibagué (Colombia). Revista INVI, 25(68), 59-96. doi:10.4067/ S0718-83582010000100003

Wilson, W. J. (2012). The truly disadvantaged: The inner city, the underclass, and public policy. Chicago: University of Chicago Press. 